\title{
Challenges to become a competent burn nurse in Helsinki Burn Centre
}

\author{
Gigante-Bounid, M. RN, Niskanen, K. RN, Siivonen, H. NM, Vuola, J. MD, PhD, IImarinen, S. NM
} Helsinki Burn Centre

\section{Objectives}

In January 2016, Helsinki Burn Centre moved to a new location and unified with a previously existing general ICU. The new unit has an ICU for burn and general patients, a burn ward and an outpatient clinic. Our goal is to present challenges in the process to become a competent burn nurse in our unit called U2.

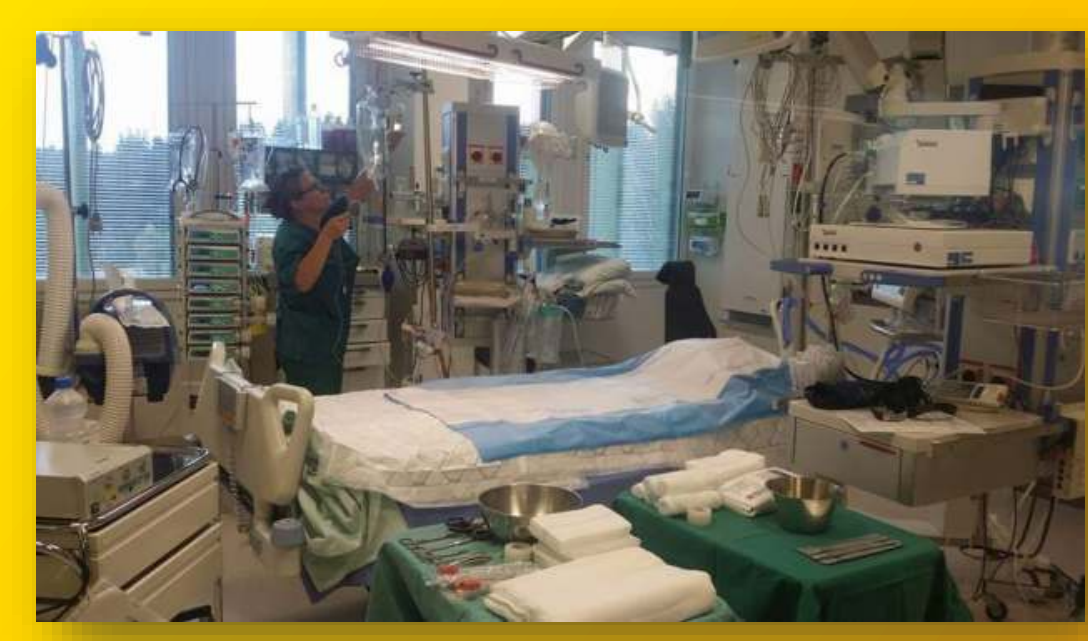

Getting ready to receive a new ICU burn patient.

\section{Results}

According to clinical studies, it takes approximately 2-3 years to become competent in critical care nursing alone. It takes more time than is shown in studies to become a competent burn nurse in an institution like ours.

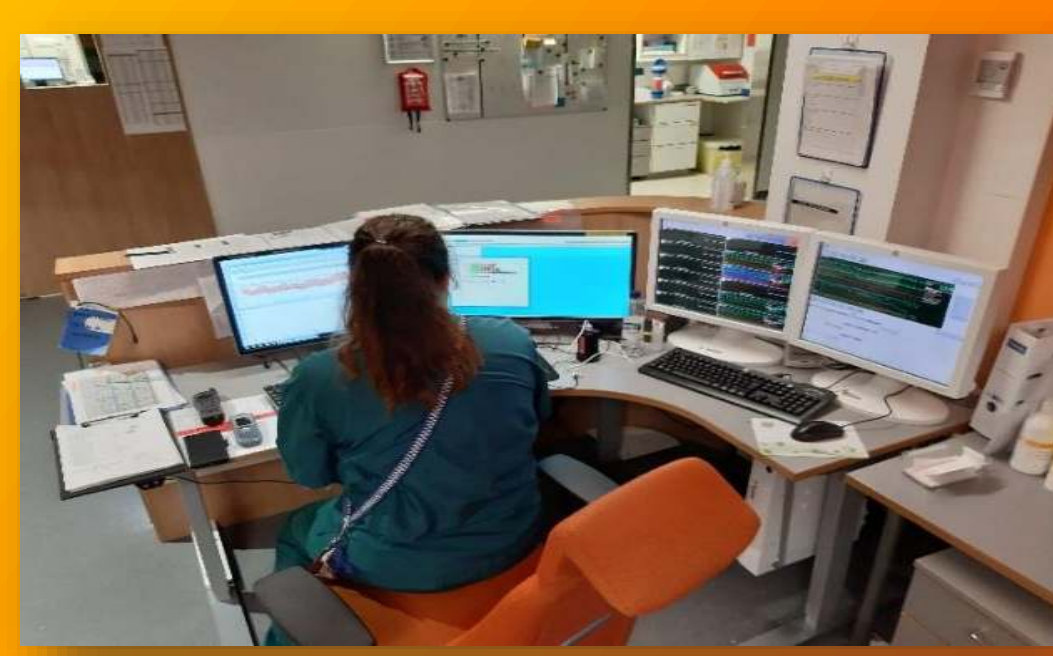

A shift manager coordinates whole U2 unit.

Sources:

Benner P. (1984). From Novice to Expert. Excellence and Power in Clinical Nursing Practice. Menlo Park: Addison-Wesley Publishing Company.

Meretoja R, Isoaho H, Leino-Kilpi H. (2004a). Nurse Competence Scale: development and psychometric testing. Journal of Advanced Nursing; 47: 124-133.

Alastalo M, Salminen L, Jeon Y, Vahlberg T, Leino-Kilpi H. (2019). Critical care nurses' self-assessed patient observation skills: a cross-sectional survey study. British Association of Critical Care Nurses: 1-8.

U2 manual. (2017). Unit U2. Helsinki University Hospital.

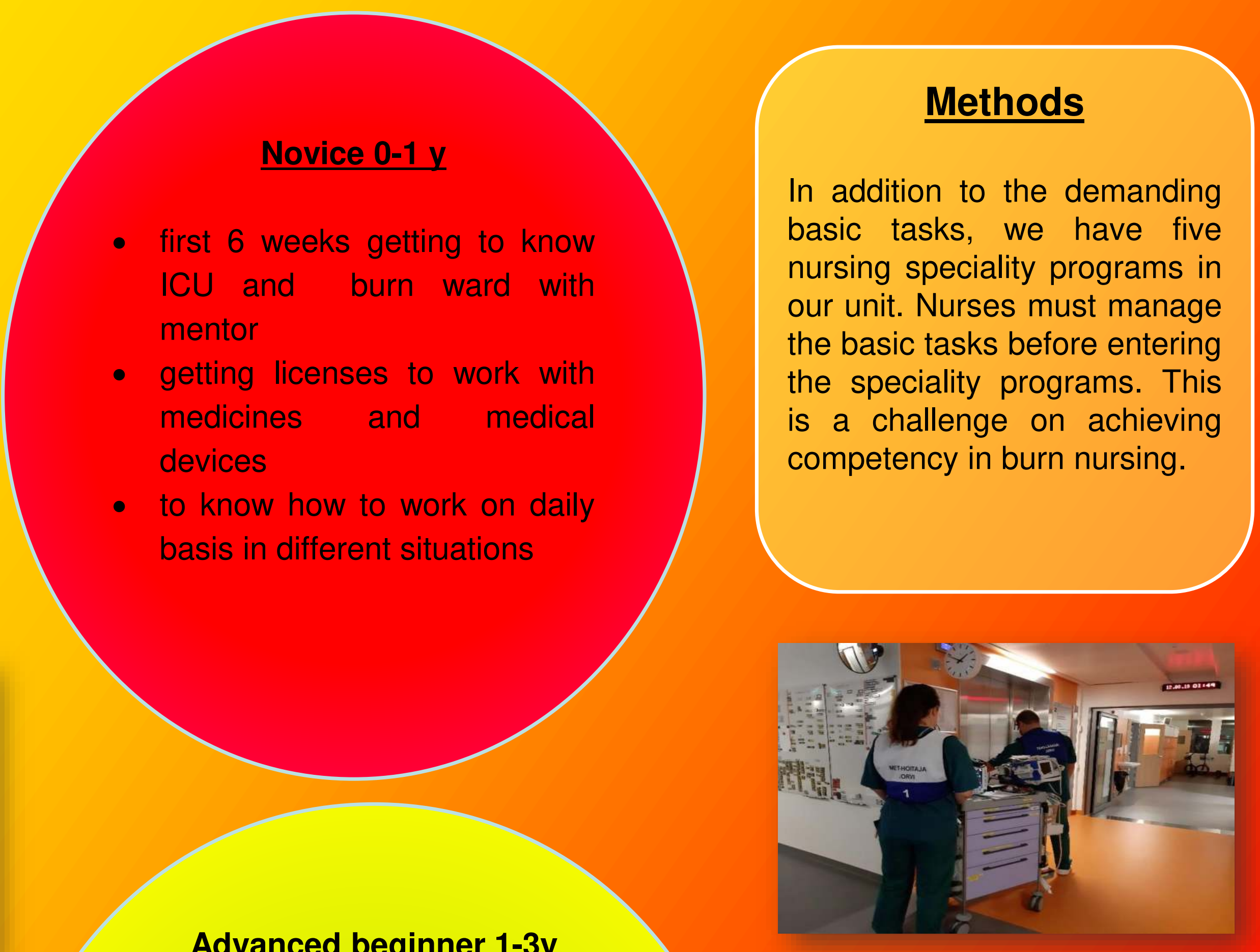

Medical emergency team: Anesthesiologist and registered nurse leaving for a task. treatment of different patient groups and manage demanding basic tasks

- depending on nurse's personal career path, nurse starts to enter speciality programs (MET, shift manager, dialysis, burn nursing)

- EMSB course

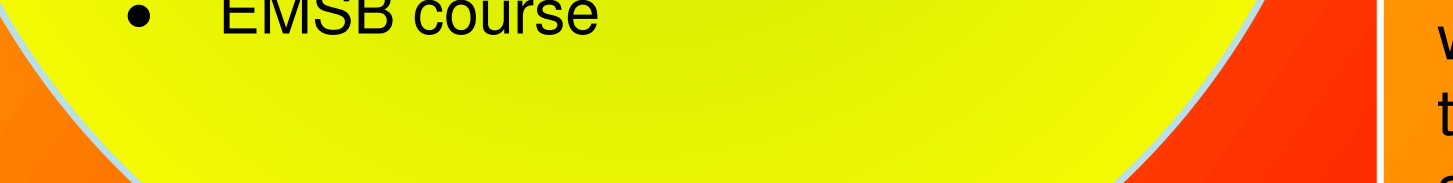
strengthen the nurses' expertise in this field.

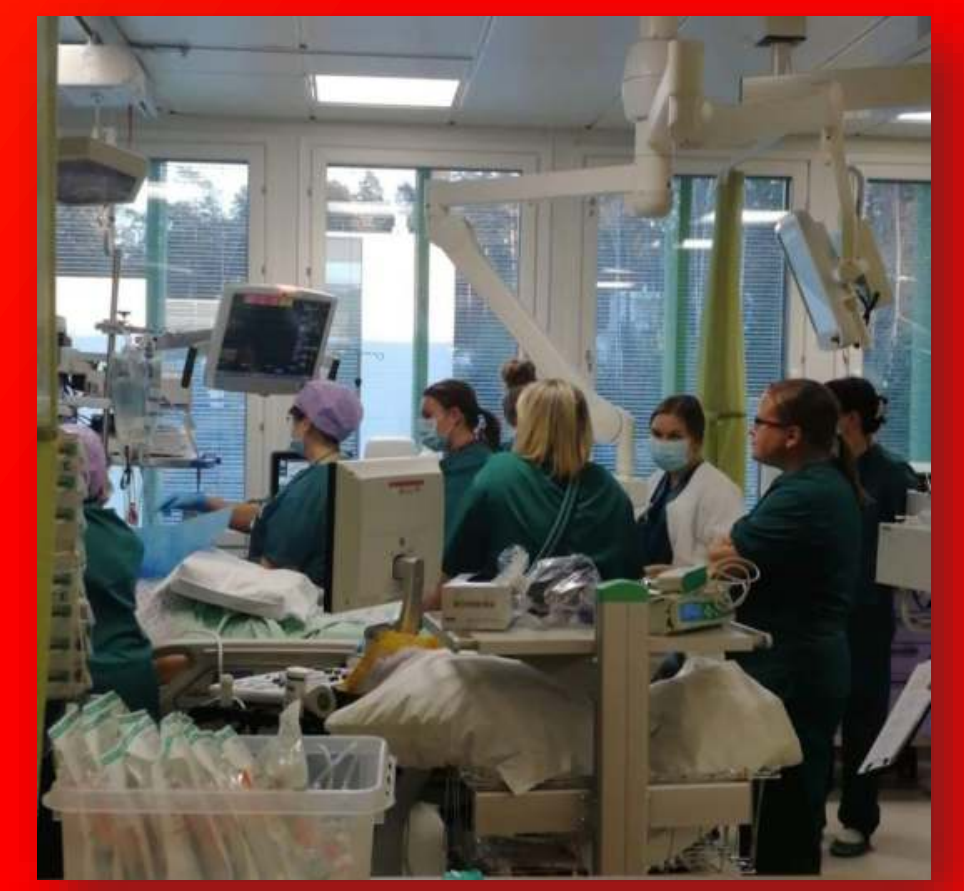

Teaching session on how to use a pulmonary artery catheter 